\title{
Investigating Optimal Location of DSSC to Minimize Reactive Power
} Generation

\author{
${ }^{* 1}$ S. R. Gaigowal, ${ }^{2}$ M. M. Renge, ${ }^{3}$ Sandeep Bhongade, ${ }^{4}$ R. S. Khonde \\ ${ }^{1,4}$ Yeshwantrao Chavan College of Engineering, Nagpur \\ ${ }^{2}$ Ramdeobaba College of Engineering and Management, Nagpur \\ ${ }^{3}$ S.G.S. Institute of Technology \& Science, Indore \\ Email: ${ }^{1}$ sandeep_rg5@rediffmail.com, ${ }^{2}$ rengemm@rknec.edu, ${ }^{3}$ bhongadesandeep@gmail.com, \\ ${ }^{4}$ khonderohan@gmail.com
}

Received: 06th October 2019, Accepted: 20th November 2019, Published: 31st December 2019

\begin{abstract}
Power flow control using Distributed-FACTS provides a reliable substitute to power flow control using lumped FACTS controllers which employs high rated power electronics devices. Lumped FACTS controllers becomes very costly and reliability is also less. DSSC advantage is that it provides power flow control in cost effective and more reliable way. Distributed Static Series Compensator (DSSC) is one of the Distributed series FACTS controller employing single phase low power inverter like SSSC. Multiple number of DSSC devices is required to connect on the line to achieve noticeable current change in the line. In this paper, optimal DSSC placement in the existing line is implemented to minimize reactive power generation. System studies are presented on IEEE-14 bus system and TNEB 69 bus system.
\end{abstract}

\section{Keywords}

Distributed Static Series Compensator (DSSC), Static Synchronous Series Compensator (SSSC), Particle Swarm Optimization (PSO), Reactive power generation

\section{Introduction}

Electricity consumption is increasing day by day and generation is also increasing to match increased load demand. Whereas, Transmission network is not spread in that proportion of increased generation. As a result, existing transmission network is working either overloaded or near to its thermal limit. It may happen that some of the lines are still operating underloaded. FACTS controllers help to control power flow in the lines. FACTS controllers conventionally consists of inductor and capacitor elements. TCSC and SVC are the popular conventional FACTS controllers. New age FACTS controllers are VSC based and it is implemented with high power electronics switches. STATCOM is one of the VSC based FACTS controller gives wide power flow control. But these lumped FACTS controllers are very costly; reliability is also less [1]. Distributed FACTS controllers provide a replacement for lumped FACTS controllers.

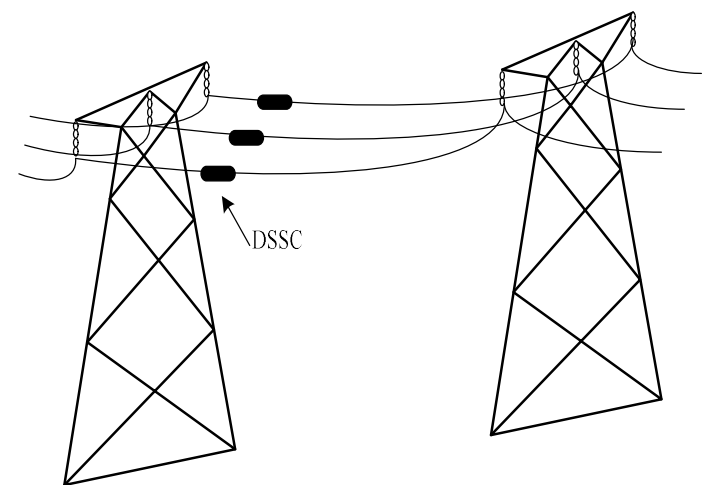

Fig.1: DSSC Hanging on Transmission Line

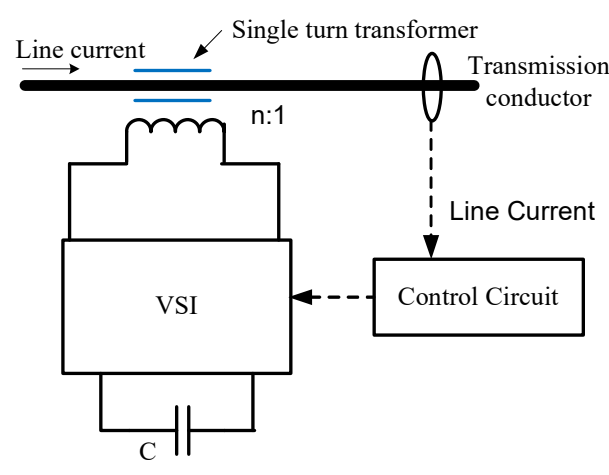

Fig.2: DSSC Circuit

DSSC is a distributed series FACTS device similar to Static Synchronous Series Compensator (SSSC) but it is low power circuit. It is first proposed in [2]. It can be attached on the existing line with the help of STT as shown in Fig. 1. It injects very small voltage in series with the line. Fig. 2 shows schematics of DSSC. It consists of single phase low power inverter and a single turn transformer (STT) to connect to line. STT is a high turns ratio transformer reducing current in inverter circuit so that low power rating power electronics switches in the inverter circuit is used. DC link capacitor at the inverter input side is charged through line current itself. DSSC is attached on the existing line with the help of STT. Like SSSC, DSSC injects voltage in series with the line in quadrature with line current in inductive and capacitive mode of operation. Since it is a low power device, a very small injected voltage gives a very small emulated reactance in series with the 
line. Some literature are cited in [3]-[7]. To achieve significant change in current, multiple DSSC's need to connect in the existing line at some specified spacing. Multiple DSSC's in the line will provide active power flow control. DSSC emulates a small inductive or capacitive reactance which alters effective line reactance and alters active power flow in the line. Optimal emulated reactance is found using Particle Swarm Optimization. Location of DSSC devices is inspected to minimize reactive power generation with optimal emulated reactance. System studies are demonstrated on IEEE-14 bus system and 69 bus TNSB system.

\section{Methodology}

Objective function is to minimize reactive power generation by employing DSSC devices on the line. Particle Swarm Optimization is applied to find optimal DSSC devices such that no line would become overloaded. For each line PSO is applied to fine optimum number of DSSC devices to reduce reactive power generation with the constraint that no line would cross its thermal limit. Tabulating all the lines with optimum DSSC devices with minimum reactive power generation. Analysing table, line will be selected with optimum devices with minimum reactive power generation.

\section{DSSC for Reactive Power Generation Optimization}

In this paper, DSSC placement is discussed to minimize reactive power generation. DSSC is emulating inductive and capacitive reactance, hence absorbing or injecting reactive power in the system. Reactive power generation of generators can be minimized by applying DSSC compensation. Various optimization problems are solved using optimization techniques. [8]-[10]. Particle swarm optimization is one of the effective optimization technique [11]-[12]. A particle swarm optimization technique is applied to find optimum emulated reactance to minimize reactive power generation. Objective function $F_{2}$ is given in eq (1).

$F_{2}=Q_{G}$

$Q_{G}$ is Reactive power generation by generators

Optimization problem is solved considering the equality and inequality constraints given as follows,

(i) Equality constraint

Power balance equation gives the total power generation satisfying load demand and the losses in transmission line. This is equality constraint given as,

$\sum_{i=1}^{n g} P_{G_{i}}-P_{D_{i}}-P_{\text {loss }}=0$

$P_{G i}$ is the $i^{\text {th }}$ generator power generation, $P_{D}$ is the total power demand, $P_{\text {Loss }}$ is the real power loss in the transmission lines and ng is the number of generators. Real power and reactive power at bus $i$ is expressed in terms of bus voltage magnitude, angle and bus admittance matrix elements as follows.

$$
\begin{aligned}
& P_{G_{i}}-P_{D_{i}}-V_{i} \sum_{j=1}^{n b} V_{j}\left[G_{i j} \cos \left(\delta_{i}-\delta_{j}\right)+B_{i j} \sin \left(\delta_{i}-\delta_{j}\right)\right]=0 \\
& Q_{G_{i}}-Q_{D_{i}}-V_{i} \sum_{j=1}^{n b} V_{j}\left[G_{i j} \sin \left(\delta_{i}-\delta_{j}\right)+B_{i j} \cos \left(\delta_{i}-\delta_{j}\right)\right]=0
\end{aligned}
$$

Nonlinear equations solve N-R power flow equations. Power loss equation is shown in equation (5).

$$
P_{\text {loss }_{i}}=\sum_{k=1}^{n l} g_{k}\left[G_{i j} \cos \left(\delta_{i}-\delta_{j}\right)+B_{i j} \sin \left(\delta_{i}-\delta_{j}\right)\right]=0
$$

(ii) Inequality constraint

For secure power system operation and control, power flow through transmission lines should not be more than transmission lines thermal limit. Lines should not be operated overloaded. Generator voltage, generated active and reactive power should be within its acceptable limits. Equation (6) shows voltage constraints and (7) shows reactive power generation constraints.

$$
\begin{aligned}
& V_{i}^{\min } \leq V_{i} \leq V_{i}^{\max } \cdots \cdots \cdot i=1,2 \ldots n \\
& Q_{G i}^{\min } \leq G_{G i} \leq Q_{G i}^{\max } \cdots \cdots \cdot i=1,2 \ldots n g
\end{aligned}
$$

(iii) FACTS constraints

DSSC is a low power device and it injects a very small voltage in the line and it gives an very small change in power. Multiple DSSC's is required to get significant power flow change. In the proposed optimization problem, Maximum DSSC devices are bounded such that it would not emulate reactance greater than $50 \%$ of line reactance. In eq. (8), $X_{D S S C}$ is the reactance emulated by DSSC and $X_{\text {Line }}$ is the actual line reactance.

$\frac{X_{D S S C}}{X_{\text {Line }}} \leq 50 \%$

\section{System Studies}

DSSC is applied on the existing line in the transmission network. Particle swarm optimization problem is solved to minimize $F_{2}$ using Matpower [13]. It will provide optimum emulated reactance on particular line to 
minimize reactive power generation. Tabulating the results showing emulated reactance with corresponding line and reactive power generation of generators. Next, a minimum generation is inspected with optimum emulated reactance on the corresponding line by analysing table.

(I) In IEEE 14 bus system [14], base load flow studies show that generator at bus 2 is participating more reactive power generation amongst other generators. Objective is formulated to reduce reactive power generation of generator at bus 2 with the constraints that no line would carry current above its thermal limit. Reactive power generation limit constraints and voltage limit constraints are incorporated in the optimization problem. DSSC is applied on every line. N-R power flow and optimization problem is run. Convergence characteristics is shown in Fig. 3. Table 2 shows reactive power generation of generator at bus 2 with DSSC placed at different lines. It is found, reactive power generation is minimum with DSSC placed in line connecting buses 1-2. It is concluded that DSSC placement on line connecting buses 1-2 shows minimum reactive power generation

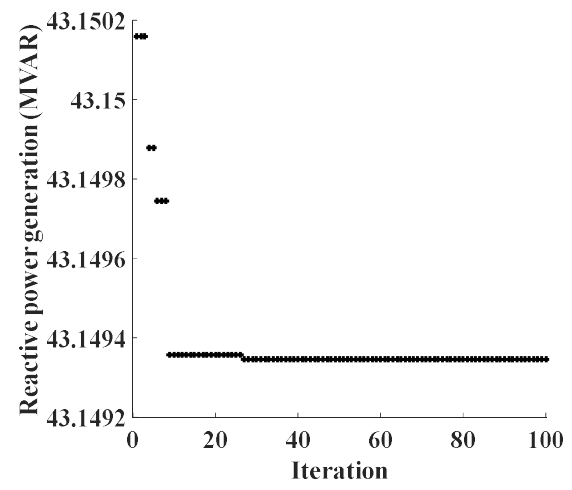

Fig. 3: Reactive Power Generation with DSSC on Line 1-5 for Maximum Loading Factor 1.19.

\begin{tabular}{|c|c|c|c|c|c|}
\hline Gen Bus & 1 & 2 & 3 & 6 & 8 \\
\hline$Q_{\text {gmin }}($ MVAR) & Slack bus & -40 & 0 & -6 & -6 \\
\hline$Q_{\text {gmax }}($ MVAR) & Slack bus & 50 & 40 & 24 & 24 \\
\hline$Q_{g}($ MVAR) & -15.223 & 47.928 & 27.758 & 23.026 & 21.03 \\
\hline
\end{tabular}

Table 1: Reactive Power Generation

\begin{tabular}{|c|c|c|c|c|}
\hline $\begin{array}{c}\text { DSSC location } \\
\text { (line) }\end{array}$ & $\begin{array}{c}\text { DSSC emulated } \\
\text { reactance }(\mathrm{pu})\end{array}$ & $\begin{array}{c}\mathrm{Q}_{\mathrm{G} 2} \\
\text { (MVAR) }\end{array}$ & $\begin{array}{c}\mathrm{P}_{\text {Loss }} \\
(\mathrm{MW})\end{array}$ & Q $_{\text {Loss }}$ (MVAR) \\
\hline $1-2$ & 0.0295 & 34.86 & 14.26 & 49.07 \\
\hline $1-5$ & 0.1115 & 43.22 & 13.84 & 49.07 \\
\hline $2-3$ & 0.0989 & 44.12 & 13.61 & 50.67 \\
\hline $2-4$ & 0.0877 & 42.92 & 14.44 & 53.77 \\
\hline $2-5$ & 0.08481 & 46.30 & 14.09 & 55.18 \\
\hline $3-4$ & 0.0834 & 43.90 & 13.73 & 56.48 \\
\hline $4-5$ & 0.0830 & 43.92 & 13.73 & 56.49 \\
\hline
\end{tabular}

Table 2: Results of Minimum Reactive Power Generation

(II) Simulation results on TNEB 69 bus system

In this, DSSC is implemented in TNEB 69 bus system, a practical system in India. It is Tamilnadu Electricity Board in India [15]-[16]. It consists of total 13 generator buses, 56 load buses and 99 interconnected lines. Base case results show that there is no line crossing its limit. DSSC's are to be implemented on the lines with the aim; minimizing reactive power generation of generator. Before that system loading is increased until lines would not cross its limit. Without DSSC compensation, maximum loading is obtained 1.46. Now, DSSC's are applied on some selected lines. Fig. 4 shows \% utilization of lines in base case and when loading is 1.46. According to this, some lines are selected which are more near to its thermal limit. Fig. 4 shows these lines with red and green markings.

Table 3 shows reactive power generation at the buses. Generator at bus1 is supplying more reactive power. Hence, DSSC's are implemented to minimize reactive power generation of generators at bus 1 . Table 4 shows reactive power generation with concerned lines with optimal DSSC emulated reactance. It is observed that when DSSC's are connected on line connecting buses 5 to 22 i.e. line 13, reactive generation of generator at bus 1 is minimum. In this case DSSC's should operate in capacitive mode of operation. 


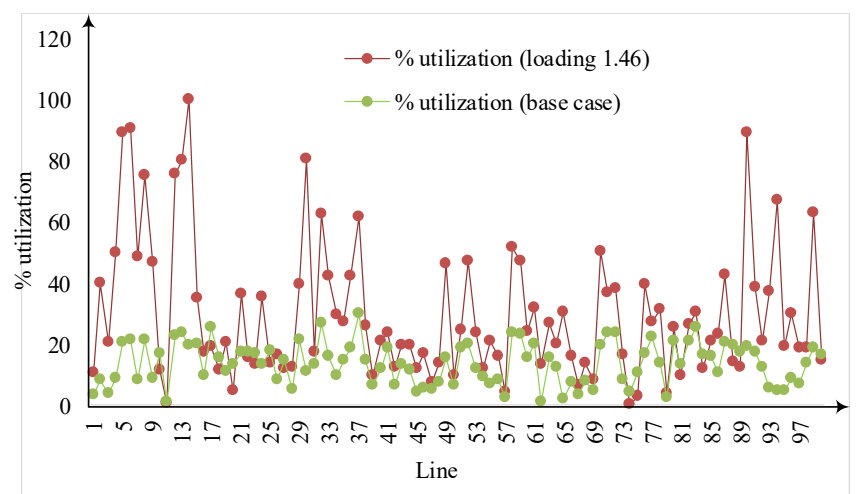

Fig. 4: TNEB 69 Bus Result (Base Case Line Current and Current When Loading is 1.46) In TNEB 69 bus system, it is observed that line connecting buses 5 to 22 i.e. line 13 will be the optimum location of DSSC to get minimum reactive power generation of generator at bus 1.

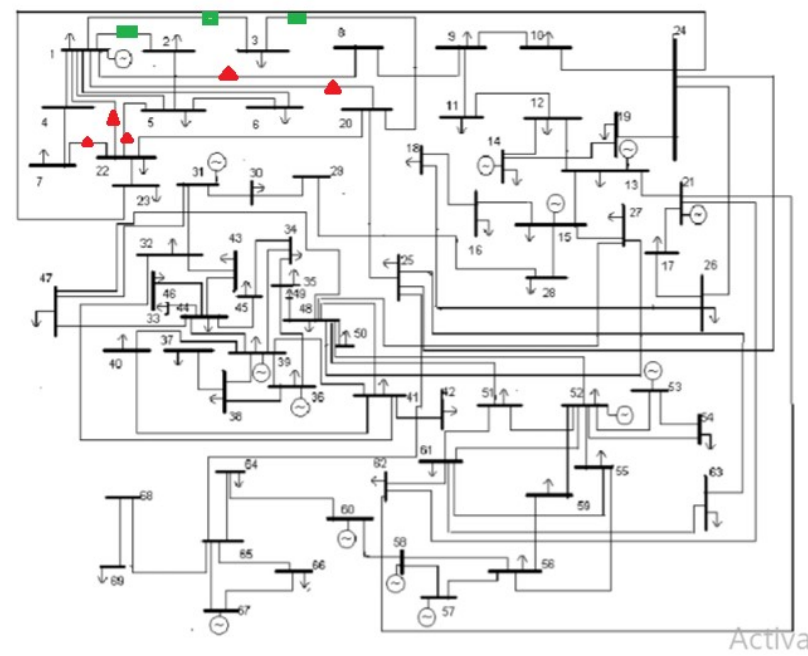

Fig. 5: TNEB 69 Bus System

\begin{tabular}{|c|c|c|c|c|c|c|c|c|c|c|c|c|c|c|}
\hline Gen & 1 & 13 & 14 & 15 & 21 & 31 & 36 & 39 & 52 & 53 & 57 & 58 & 60 & 67 \\
\hline$Q_{\text {gmin }}$ & - & 0 & - & - & - & -90 & -90 & - & - & -25 & -80 & -80 & 100 & - \\
\hline$Q_{\text {gmax }}$ & 105 & 105 & 330 & 600 & 200 & 800 & 450 & 480 & 105 & 350 & 175 & 200 & 500 & 300 \\
\hline$Q_{g}$ & 111 & 682 & 292. & 454. & 149. & 800 & 400. & 466. & 100 & 331. & 83.5 & 130. & 171. & 298 \\
\hline
\end{tabular}

\section{Conclusion}

Table 3: Reactive Power Generation of generators

In this paper, multiple DSSC devices are demonstrated in optimal way for active power flow control. Optimization is applied to find out emulated reactance by DSSC. An optimal location of DSSC placement is investigated to minimize reactive power generation with optimum emulated reactance. It can be concluded; reactive power generation is minimized considerably. Results are demonstrated on IEEE 14 bus system and TNEB 69 bus system.

\begin{tabular}{|c|c|c|c|c|c|c|c|c|}
\hline Parameters & \multicolumn{4}{|c|}{ With DSSC compensation (Capacitive reactance emulation) } \\
\hline DSSC location line & $\begin{array}{c}\text { Without } \\
\text { compensation }\end{array}$ & $1-8$ & $1-20$ & $1-22$ & $5-22$ & $7-22$ & $20-25$ & $22-69$ \\
\hline $\begin{array}{c}\text { Reactive Power generation at } \\
\text { bus 1 Qg (MVAR) }\end{array}$ & 1118 & 1027.8 & 1032.6 & 1027.5 & 1034.3 & 1024.6 & 1158.6 & 1122.5 \\
\hline $\begin{array}{c}\text { DSSC emulated reactance } \\
\text { (p.u.) }\end{array}$ & --- & 0.0452 & 0.0538 & 0.0555 & 0.03 & 0.0451 & 0.0147 & 0.0147 \\
\hline
\end{tabular}

Table 4: Results Showing Minimum Reactive Power Generation of Generator 1 in TNEB 69 Bus System (Capacitive Emulated Reactance of DSSC) 


\section{References}

1. N. G. Hingorani, L. Gyugyi, 2000 Understanding FACTS: Concepts and Technology of Flexible AC Transmission System", IEEE Press

2. D. M. Divan, W. E. Brumsickle, R. S. Schneider, B. Kranz, R. W. Gascoigne, D. T. Bradshaw, M. R. Ingram, and I. S. Grant, 2007 "A Distributed Static Series Compensator for realizing active power flow control on existing power lines", IEEE Trans. on Power system, vol. 22, no. 1, pp. 642-649.

3. Z. Yuan, Sjoerd, W. H. de Haan, Jan Braham Ferreira, “A FACTS device: Distributed power flow controller (DPFC)", IEEE Trans. on Power Electronics, vol. 25, no. 10, Oct. 2010, pp. 2564-2572.

4. S. R. Gaigowal, M. M. Renge, 2016, "Distributed Power Flow Controller using single phase DSSC to realize active power flow control through transmission line," IEEE Conference on Computation of Power, Energy Information \&Communication (ICCPEIC), pp. 747-751

5. Sandeep R. Gaigowal, Dr. M. M. Renge, 2013 "Some studies of Distributed Series FACTS Controller to control active power flow through Transmission Line", IEEE International Conference on Power, Energy and Control (ICPEC), pp 124-128.

6. H. Johal and D. Divan, 2007, "Design considerations for series connected distributed FACTS converters," IEEE Trans, Ind., Appl., vol. 43, no. 6, pp. 1609-1618.

7. Alexander Brissette, Dragan Maksimović, Yoash Levron, 2015 "Distributed Series Static Compensator deployment using a linearized transmission system model,” IEEE Trans. on Power Delivery, vol.30, no.3, pp. $1269-1277$

8. M. A. Abido, 2006, "Multiobjective Evolutionary Algorithms for Electric Power Dispatch Problem," IEEE Transactions on Evolutionary Computation, vol. 10, no. 3, June, pp. 315-329

9. A. Lashkar Ara, A. Kazemi, S. A. Nabavi Niaki, 2012, "Multi objective Optimal Location of FACTS ShuntSeries Controllers for Power System Operation Planning," IEEE Transaction on Power Delivery, VOL. 27, NO.2, April, pp. 481-490

10. Xiao-Ping Zhang, 2003, "Advanced Modeling of the Multicontrol Functional Static Synchronous Series Compensator (SSSC) in Newton Power Flow," IEEE Trans. on Power Systems, vol. 18, no. 4, Nov., pp. $1410-1416$

11. Z. Gaing, 2003, "Particle swarm optimization to solving the economic dispatch considering the generator constraints," IEEE Transactions on Power Systems, vol. 18, issue 3, Aug. , pp. 1187-1195.

12. Yamille del Valle, Ganesh Kumar Venayagamoorthy, Salman Mohagheghi, Jean-Carlos Hernandez, Ronald G. Harley, 2008, "Particle Swarm Optimization: Basic Concepts, Variants and Applications in Power Systems," IEEE Transactions on Evolutionary Computation, vol. 12, no. 2, pp. 171-195

13. R.D. Zimerman, C.E. Murillo-Sanchez, and D. Gam, MATPOWR - A MATLAB Power System Simulation Package, Version 3, http://www.pserc.cornell.edu/matpower.

14. Power Systems Test Case Archive. 2008. (Online) available: http://www.ee.washington.edu/research/pstca

15. Tamil Nadu Electricity Board Statistics at a Glance 2003-2004, Planning Wing of Tamil Nadu Electricity Board, Chennai, India.

16. R. Kanimozhi and K. Selvi, 2013, “A Novel Line Stability Index for Voltage Stability Analysis and Contingency Ranking in Power System Using Fuzzy Based Load Flow", Int. Journal of Electrical Engineering Tech. vol. 8, no. 4: 694-703 